\title{
Transcriptome and metabolite profiling reveals the effects of Funneliformis mosseae on the roots of continuously cropped soybeans
}

Cheng-Cheng Lu ${ }^{1+}, \mathrm{Na} \mathrm{Guo}^{2+}$, Chao Yang ${ }^{1}$, Hai-Bing Sun ${ }^{1}$ and Bai-Yan Cai ${ }^{1,2^{*}}$ (D)

\begin{abstract}
Background: Arbuscular mycorrhizal fungi are the most widely distributed mycorrhizal fungi, which can form mycorrhizal symbionts with plant roots and enhance plant stress resistance by regulating host metabolic activities. In this paper, the RNA sequencing and ultra-performance liquid chromatography (UPLC) coupled with tandem mass spectrometry (MS/MS) technologies were used to study the transcriptome and metabolite profiles of the roots of continuously cropped soybeans that were infected with F. mosseae and F. oxysporum. The objective was to explore the effects of $F$. mosseae treatment on soybean root rot infected with F. oxysporum.

Results: According to the transcriptome profiles, 24,285 differentially expressed genes (DEGs) were identified, and the expression of genes encoding phenylalanine ammonia lyase (PAL), trans-cinnamate monooxygenase (CYP73A), cinnamyl-CoA reductase $(C C R)$, chalcone isomerase $(C H)$ and coffee-coenzyme o-methyltransferase were upregulated after being infected with F. oxysporum; these changes were key to the induction of the soybean's defence response. The metabolite results showed that daidzein and 7,4-dihydroxy, 6-methoxy isoflavone (glycine), which are involved in the isoflavone metabolic pathway, were upregulated after the roots were inoculated with $F$. mosseae. In addition, a substantial alteration in the abundance of amino acids, phenolic and terpene metabolites all led to the synthesis of defence compounds. An integrated analysis of the metabolic and transcriptomic data revealed that substantial alterations in the abundance of most of the intermediate metabolites and enzymes changed substantially under pathogen infection. These changes included the isoflavonoid biosynthesis pathway, which suggests that isoflavonoid biosynthesis plays an important role in the soybean root response.

(Continued on next page)
\end{abstract}

\footnotetext{
* Correspondence: caibaiyan@126.com

${ }^{+}$Cheng-Cheng Lu and Na Guo contributed equally to this work and share first authorship

${ }^{1}$ Heilongjiang Provincial Key Laboratory of Ecological Restoration and Resource Utilization for Cold Region, College of Life Sciences, Heilongjiang University, Harbin 150080, People's Republic of China

${ }^{2}$ Department of Food and Environment Engineering, Heilongjiang East

University, Harbin 150086, People's Republic of China
}

(c) The Author(s). 2020 Open Access This article is licensed under a Creative Commons Attribution 4.0 International License, which permits use, sharing, adaptation, distribution and reproduction in any medium or format, as long as you give appropriate credit to the original author(s) and the source, provide a link to the Creative Commons licence, and indicate if changes were made. The images or other third party material in this article are included in the article's Creative Commons licence, unless indicated otherwise in a credit line to the material. If material is not included in the article's Creative Commons licence and your intended use is not permitted by statutory regulation or exceeds the permitted use, you will need to obtain permission directly from the copyright holder. To view a copy of this licence, visit http://creativecommons.org/licenses/by/4.0/ The Creative Commons Public Domain Dedication waiver (http://creativecommons.org/publicdomain/zero/1.0/) applies to the data made available in this article, unless otherwise stated in a credit line to the data. 
(Continued from previous page)

Conclusion: The results showed that F. mosseae could alleviate the root rot caused by continuous cropping. The increased activity of some disease-resistant genes and disease-resistant metabolites may partly account for the ability of the plants to resist diseases. This study provides new insights into the molecular mechanism by which AMF alleviates soybean root rot, which is important in agriculture.

Keywords: Soybean root rot, Funneliformis mosseae, Fusarium oxysporum, Transcriptome, Metabolite profiling

\section{Background}

Soybean (Glycine max L.) root rot is a kind of crop disease that is widely distributed, causes serious damage and is difficult to control. Its incidence can reach approximately $75 \% \sim 90 \%$, which leads to declining soybean yields and quality [39]. The pathogenic fungi that cause soybean root rot include Fusarium oxysporum, Fusarium avenaceum, Fusarium solanacearum, Fusarium merismoides, Phytophthora sojae and Pythium ultimum [16]. F. oxysporum is the dominant fungus of soybean root rot, and it can reduce the number of soybean pods and the yields between $25 \% \sim 75 \%$ [57]. Studies have shown that the fungicides could control the disease incidence in a greenhouse experiment, but they had no effect on increasing production in the field [14].

Microorganisms have biocontrol potential against plant diseases (Babu et al., [2]). Arbuscular mycorrhizal fungi (AMF) are obligate mutualistic fungi, which can form mycorrhizal symbionts with the roots of over $80 \%$ of terrestrial plants. AMF can not only enhance plants' absorption of nutrients and minerals, but also improve the ability of plants to resist soil-borne disease, and plays an important role in plant evolution and nutrition [7, 19, 36]. Funneliformis mosseae as one dominant AMF, has a positive effect on plant tolerance to root pathogens. In 1968, Safir first discovered that $F$. mosseae could reduce the incidence rate of onion (Allium cepa L.) root rot caused by Pyrenochaeta terrestris [42], and later investigators have successfully applied it to citrus (Citrus reticulata Blanco), peaches (Amygdalus persica L.), strawberries (Fragaria ananassa Duch.), soybeans and other crops. For example, the root rot caused by F. oxysporum in cucumber (Cucumis sativa L.) seedlings [47] and the root rot caused by Meloidogyne incognita and Macrophomina phaseolina in chickpeas [44] as well as aboveground plant diseases such as powdery mildew (Erysiphe pisi) in Elymus sibircus [10] and Fusarium wilt in cucumbers have been studied in this context [11].

The transcriptome can be used to reveal the mechanism of metabolic regulation at the molecular level, and it has become an indispensable method for studying gene expression, RNA biogenesis and metabolism [49, 50]. Metabolomics is an emerging omics technology, it is applied to identify and quantify all the metabolites in an organism or in cells, and is a component of systems biology [24]. This tool is a bridge to link genes, proteins, and phenotypes. Thus far, metabolomics has been gradually applied in various fields of agriculture and has been demonstrated to be a powerful tool to determine the metabolic profile of biological samples through targeted or untargeted analyses [22]. Agudeloromero combined transcriptome and metabolite analysed the response of grapes (Vitis vinifera L.) against the pathogen, which bring novel insights into the responses of fruits during a pathogen-host interaction [1]. By integrating proteome and metabolite profiling with cell wall properties, Floerl $\mathrm{S}$ et al. found that Verticillium longisporum might enhance its own pathogenicity by negatively regulating and delaying the induction and expression of plant defence genes [8].

Owing to the increased demand for soybeans and the enhanced risk of crop losses caused by $F$. oxysporum, it is necessary to find disease control ways that could be used in soybean production systems as soon as possible. The purpose of this study is to combine transcriptome and metabolite profiling to explore the effect of $F$. mosseae on soybean root rot through pot experiments and to determine whether AMF could alleviate the damage from $F$. oxysporum-derived soybean root rot. In addition, other purposes are to reduce the incidence of soybean root rot, alleviate the obstacles to continuous cropping, provide a test basis for elucidating the pathogenesis of soybean root rot, and provide a theoretical basis for the development and application of biological agents.

\section{Results}

Impact of $F$. mosseae treatments on the root rot grade and colonization rate of soybean roots

Forty-four days after sowing, the roots of soybeans in each treatment group were randomly sampled to detect the incidence of root rot. Figure 1 shows that the disease index increased in $\mathrm{F}$ group, with the growth and development of the soybeans. After F. mosseae inoculation, the disease index of AF group was lower than that of $F$ group, which indicated that $F$. mosseae could alleviate the symptoms of soybean root rot.

As shown in Fig. 2, the colonization rate of AMF was not detected until the soybeans had grown for $40 \mathrm{~d}$, and the colonization rate increased in all the groups. The colonization rate in AF was significantly higher than it 


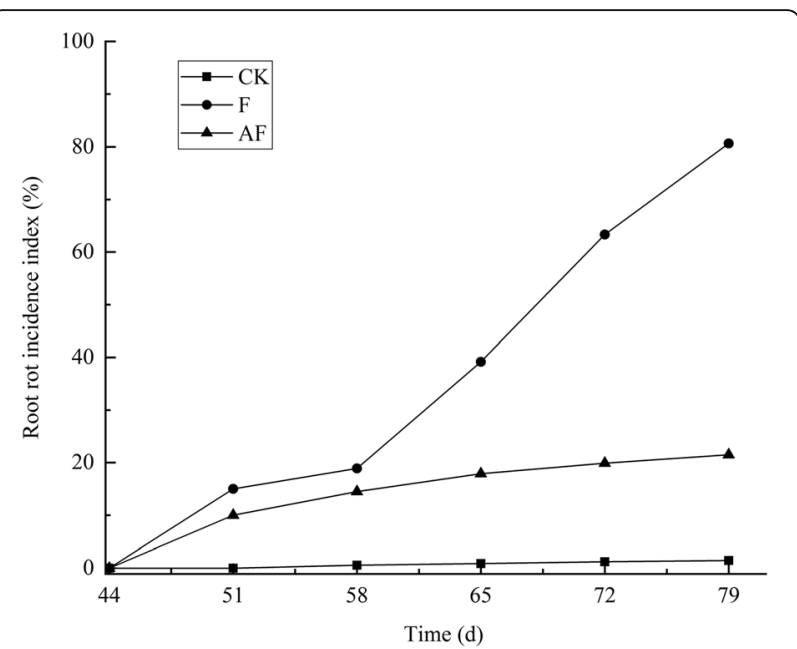

Fig. 1 Root rot incidence index in potted-experiments of continuously cropped soybeans. Squares, circles, and triangles represent samples from the CK, F, and AF groups, respectively. CK means soybean were planted the normal sterilized soil; $F$ means soybean seeds were inoculated with F. oxysporum spore suspension; AF means soybean seeds were inoculated with F. mosseae +F. oxysporum. Note: All experiments were conducted in potted-experiments. $X$-axis represents which day detected the root rot incidence index of soybean. Y-axis represents the root rot incidence index

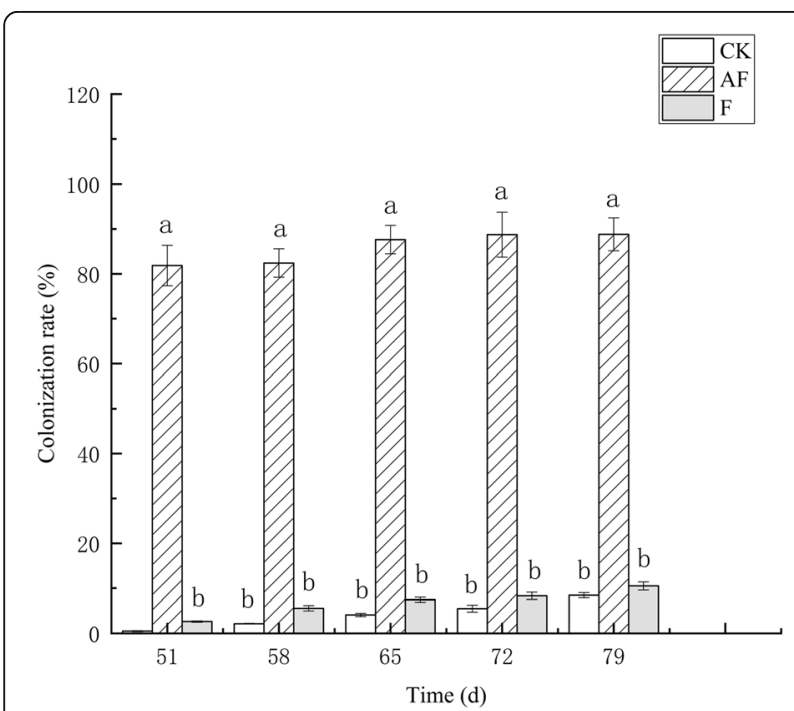

Fig. 2 AMF colonization rate of continuously cropped soybeans in potted-experiments. White, gray and stripes represent samples from the CK, F, and AF groups, respectively. CK means soybean were planted the normal sterilized soil; F means soybean seeds were inoculated with F. oxysporum spore suspension; AF means soybean seeds were inoculated with F. mosseae $F$. oxysporum. Note: All experiments were conducted in potted-experiments. $X$-axis represents which day detected the AMF colonization rate of continuously cropped soybean roots. Y-axis represents the AMF colonization rate. The data shown here are the averages for three plants under each condition and the error bars represent standard deviations. Bars subtended by the same lowercase letter do not differ significantly at $p<0.05$ according to Tukey's test was in the CK and F groups $(N=2, P=0.044)$. After 58 $\mathrm{d}$, the mycorrhizal structure that formed in the AF group gradually increased, and a large number of hyphae and vesicles appeared. Clearly, the colonization rate of $\mathrm{F}$ and CK was significantly lower than that of AF. We speculate that the roots infected in these two groups were by the spore transmission of fungi spores in the air.

\section{Impact of $F$. mosseae treatments on the soybean root transcriptome}

Nine root samples were transcriptome-sequenced during the high-incidence period of root rot. The number of high-quality clean reads accounted for more than $98 \%$ of the samples in each group (Supplementary Table S1). The high-quality clean reads obtained here were compared with known genomes. Last, 38,961, 38,832 and 38, 688 genes were detected in the $\mathrm{AF}, \mathrm{CK}$ and $\mathrm{F}$ treatments, and the number of genes detected in each group is shown in Table 1.

To assess the reproducibility of soybean DEGs library, a principal component analysis was performed on the transcriptome profiles of the 9 analysed samples. The dispersion degree of $\mathrm{F}$ group was the best in PC1 and $\mathrm{PC} 2$, followed by CK group. Although the dispersion degree of CK3 was relatively large, its dispersion was within a reasonable range on $\mathrm{PC}$. In the AF group, AF3 become an outlier. To improve the repeatability among the three samples, the PCA analysis of each component was performed again after AF3 was removed (Fig. 3a). It can be seen that the dispersion degree of each component on PC1 (66.1\%) is almost consistent, and the samples show good repeatability. After RNA-seq sequencing, to express $\mathrm{CK}, \mathrm{F}$ and AF quantitatively, edge $\mathrm{R}$ software was used to analyse the DEGs between CK, F and AF groups (Fig. 3b). The different expression patterns among the three groups revealed that the difference between the F and AF groups was the largest (4477 downregulated transcripts and 7085 upregulated transcripts). In addition, when comparing CK and F, 5728 transcripts were upregulated and 4376 were downregulated.

We annotated and classified DEGs from three aspects: biological process (BP), molecular function (MF) and cellular component (CC) according to Gene Ontology. The GO terms of the DEGs in the CK vs. F groups were categorized into 44 primary functional groups (Fig. 4a). In the BP category, most DEGs were primarily

Table 1 Number of genes detected in each treatment

\begin{tabular}{llll}
\hline $\begin{array}{l}\text { Group } \\
\text { name }\end{array}$ & $\begin{array}{l}\text { Number of known } \\
\text { genes }\end{array}$ & $\begin{array}{l}\text { Number of new } \\
\text { genes }\end{array}$ & $\begin{array}{l}\text { Total number of } \\
\text { genes }\end{array}$ \\
\hline AF & $38,961(82.91 \%)$ & 2313 & 41,274 \\
CK & $38,832(82.63 \%)$ & 2298 & 41,130 \\
F & $38,688(82.33 \%)$ & 2284 & 40,792 \\
\hline
\end{tabular}




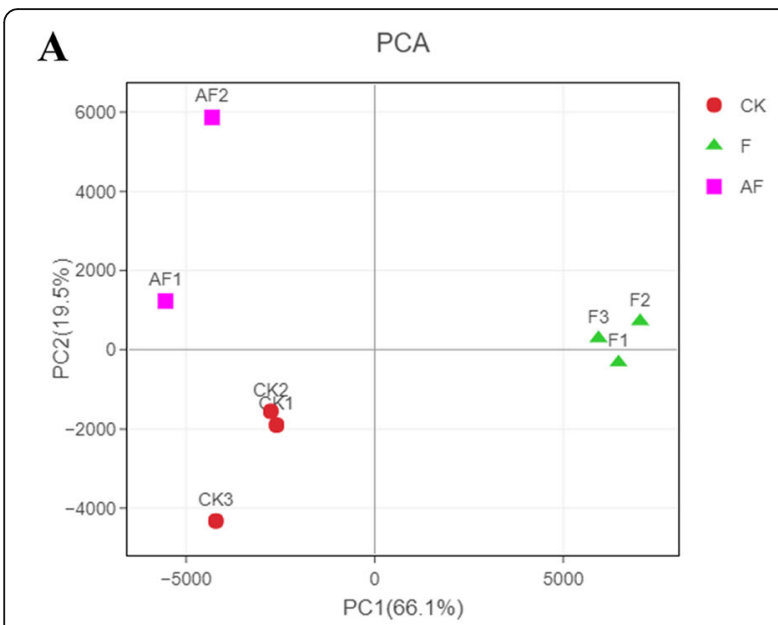

B

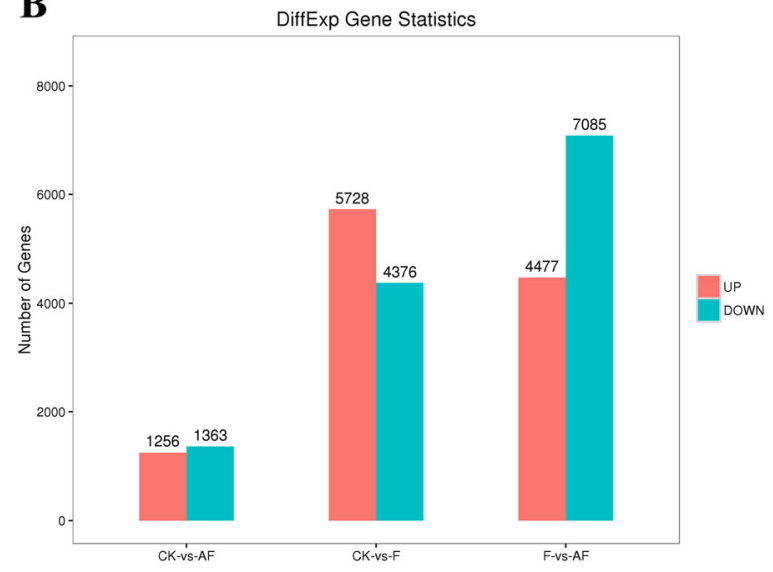

Fig. 3 Transcriptome analysis of continuously cropped soybean roots during the high incidence of soybean root rot. a. Principal component analysis (PCA) on the soybean transcriptome of 9 independent samples collected from soybean roots. Circles, triangles and squares represent samples from the CK, F, and AF groups, respectively. b. Principal component analysis (PCA) between samples after removing the discrete sample AF3. c. Statistical histogram of differentially expressed genes in continuously cropped soybean roots between different groups. FDR $<$ 0.05 and $|\log 2 \mathrm{FC}|>1$ were used to screen differentially expressed genes. The red bar represents the percentage of upregulated genes, and the green bar represents the percentage of downregulated genes

concentrated on metabolic processes (12.67\%) and cellular processes (10.57\%). In the MF category, DEGs were primarily involved in coding catalytic activity $(11.80 \%)$, followed by binding activity (8.92\%). In the CC category, the upregulated DEGs were largely related to cell part $(12.36 \%)$ and organelle (4.24\%), while a few DEGs are involved in extracellular matrix (0.01\%) and supramolecular fibers $(0.005 \%)$. These results indicate that pathogens invade the cells of the soybean roots by destroying the membrane system, and then they disrupt the metabolic process of the soybeans and a series of physiological and biochemical reactions.

The GO terms of the DEGs were categorized into 46 primary functional groups in the F vs. AF groups (Fig. 4b). In the BP category, most DEGs were also primarily concentrated in the response process to stimulus (2.74\%) and single-organism processes $(8.39 \%)$, in additional to metabolic processes $(12.68 \%)$ and cellular processes (10.54\%). In the MF category, DEGs were primarily involved in coding catalytic activity (11.45\%), followed by binding activity (8.76\%). In the CC category, most of the DEGs were involved in coding organelle part (6.47\%), cell components (9.94\%) and cell membrane composition (7.04\%), while few DEGs were associated with the extracellular region $(0.23 \%)$ and supramolecular fibres $(0.01 \%)$. After the $F$. mosseae inoculation, the DEGs were not only concentrated in GO terms related to the membrane system but also in GO terms related to the growth and development of soybeans, detoxification, antioxidants, etc., from the GO classification level, revealing the growth-promoting effect of $F$. mosseae on the soybeans.

Instead of performing their functions independently, genes always coordinate with each other and perform a series of regulatory functions. Using the identified soybean root genes as the background, a KEGG enrichment analysis of significantly different genes can further clarify the functions of genes in metabolic pathways. The DEGs in the $\mathrm{CK}$ vs. $\mathrm{F}$ and $\mathrm{F}$ vs. AF groups were enriched in 131 and 132 KEGG metabolic pathways, respectively. With a $p$-value $<0.05$ and an FDR $<0.05$, metabolic and signal transduction pathways with significant changes were identified, and the top 20 metabolic pathways of the $\mathrm{CK}$ vs. $\mathrm{F}$ and $\mathrm{F}$ vs. AF groups are visually displayed by scatter diagram (Fig. 5).

Among the 131 pathways shown for CK vs. F (Supplementary Table S2), the three containing the highest numbers of DEGs were "metabolic pathways" (990 DEGs, 42.45\%), "biosynthesis of secondary metabolites" (669 DEGs, 28.69\%) and "ribosome" (304 DEGs, $13.04 \%)$. Other GO terms associated with high numbers of DEGs were "phenylpropanoid biosynthesis" (155 DEGs, 6.65\%) and "plant-pathogen interaction" (104 DEGs, 4.46\%). We found that genes involved in plant pathogen interactions, such as pathogenesis-related protein 1, mitogen-activated protein kinase kinase 1 , and heat shock protein $90 \mathrm{kDa}$ beta, were upregulated. In addition, genes encoding trans-cinnamate monooxygenase (CYP73A), cinnamyl-CoA reductase (CCR), and phenylalanine ammonia lyase (PAL) were also upregulated in the phenylpropanoid biosynthesis pathway, which indicated that the $F$. oxysporum infection induced the defence response in the soybeans.

Among the 132 pathways shown for F vs. AF (Supplementary Table S3), those containing the highest numbers of DEGs were "metabolic pathways" (1133 DEGs, 41.49\%), "biosynthesis of secondary metabolites" (758 DEGs, 27.76\%) and "ribosome" (392 DEGs, $14.35 \%)$. In addition, other GO terms associated with 
Level2 GO terms of CK-vs-F

A

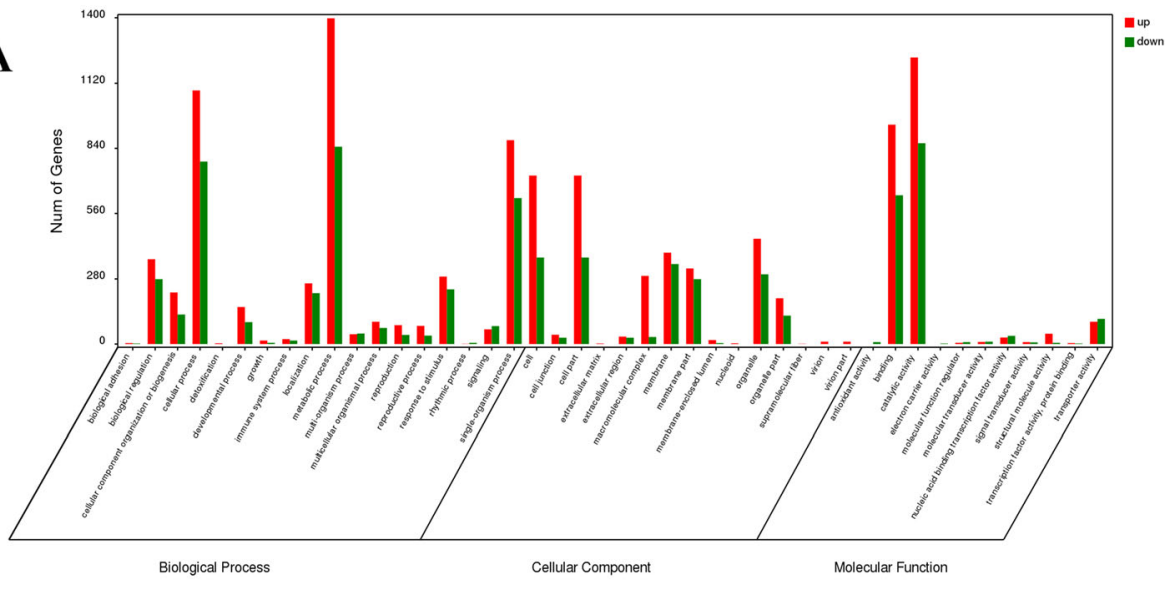

Level2 GO terms of F-vs-AF

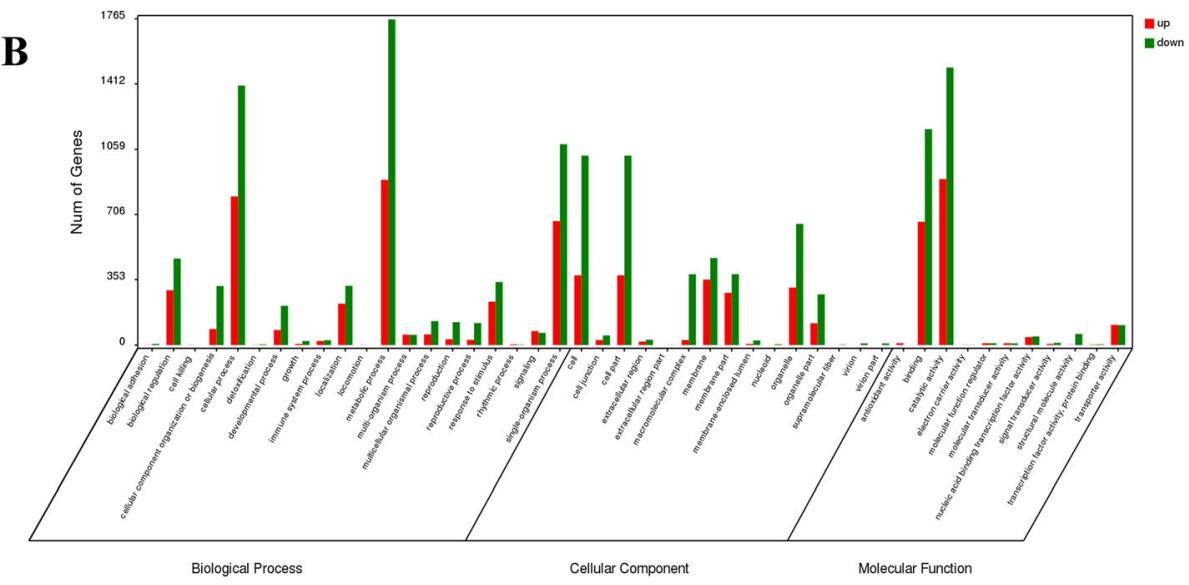

Fig. 4 GO distribution of transcripts in continuously cropped soybean roots with different treatments during the high incidence of root rot. GO categories that were significantly enriched were analysed for their level of significance in a pair-wise comparison (A: CK vs. F and B: $F$ vs. AF). The transcripts were annotated into three primary categories, namely, cellular component, biological process and molecular function. The $\mathrm{x}$-axis indicates different GO terms. The $y$-axis represents the number of genes in the indicated categories. The red bar represents the percentage of upregulated genes, and the green bar represents the percentage of downregulated genes

high numbers of DEGs were "biosynthesis of antibiotics" (303 DEGs, 11.09\%) and "carbon metabolism" (185 DEGs, 6.77\%). It is worth noting that genes that control the synthesis of phenylpropane, such as $P A L$, CYP73A, CCR, and coffee-coenzyme omethyltransferase, showed a downregulated trend, in contrast to the CK vs. F group. The same is true of genes that control chalcone isomerase $(\mathrm{CHI})$ synthesis in the flavonoid biosynthesis pathway and genes involved in the plant-pathogen interaction pathway. Therefore, it can be speculated that after AMF infection, the expression of $F$. mosseae-induced resistant enzyme genes were upregulated, and the continuous cultivation disease was alleviated by the action of $F$. mosseae, so the originally upregulated gene displayed the opposite expression trend.

\section{Impact of $F$. mosseae treatments on metabolite profiling}

The multi-response monitoring (MRM) mode showing the multi-peak metabolite detection diagram (Supplementary Fig. S1) displays the substances that can be detected in the sample. The OPLS-DA model was used to screen which metabolites had significant changes (Supplementary Fig. S2). CK vs. F group and F vs. AF group scored 41 and 46 respectively in PC1. The dispersion of components was good in each group and there was a strong correlation between samples. Owing to multivariate statistical analysis sometimes showed overfitting, OPLS-DA models were further verified by cross validation and permutation test. According to VIP $\geq 1.0$ and $\mid \mathrm{p}$ (corr) $\mid>0.5$ to the OPLS-DA model and $p$ value < 0.05 to the t-test, a total of 622 different metabolites were detected, as shown in Table 2, with 29 classes, 


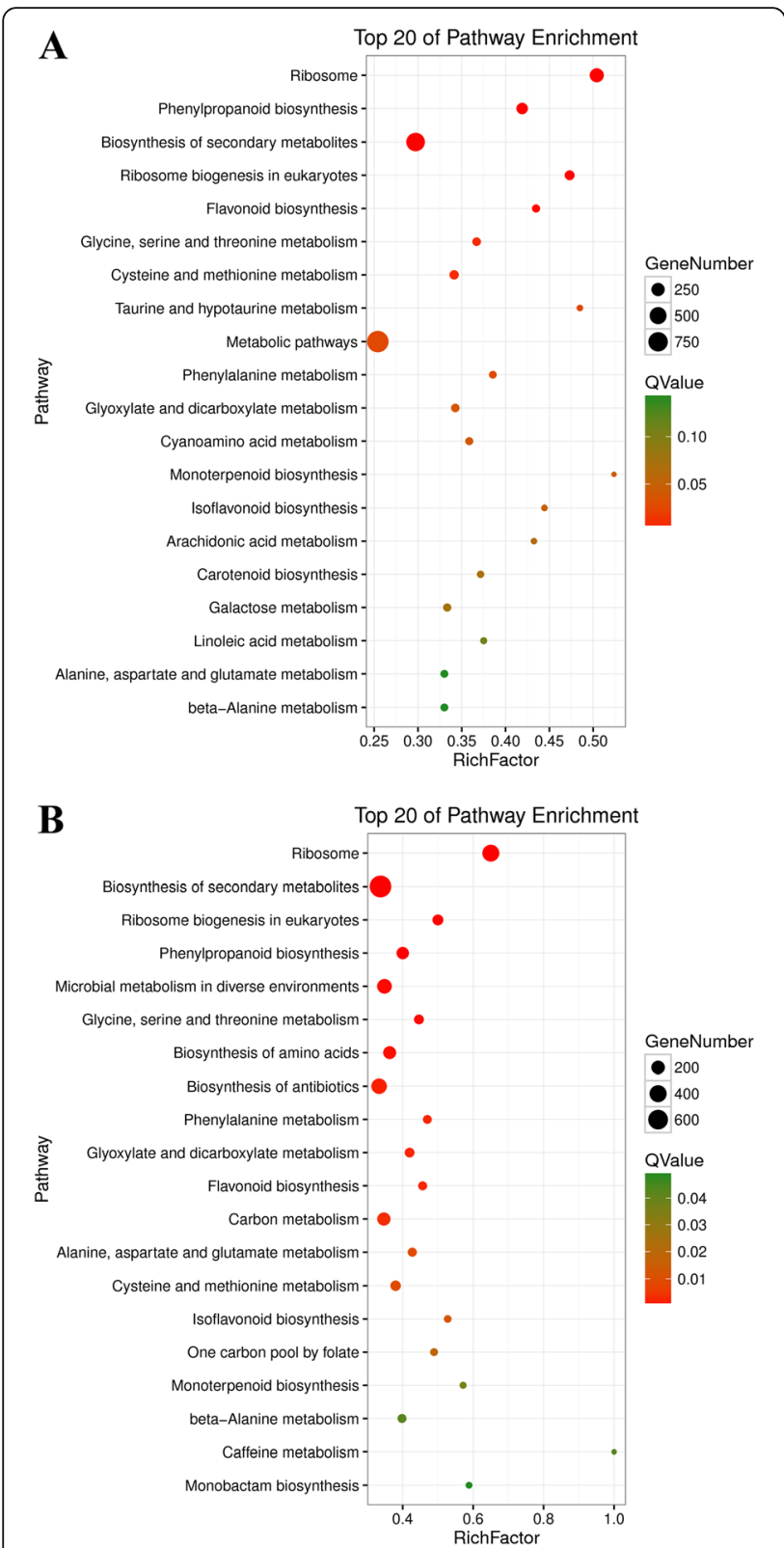

Fig. 5 Statistical scatter diagram of KEGG pathway enrichment in CK vs. F A and F vs. AF B. The size of the points represents the number of differentially expressed genes, and different colours represent different Q-values. The larger the rich factor is, the higher the degree of enrichment. The Q-value is the P-value after multiple hypothesis testing and correction. The value range is 0 to 1 . The closer to zero the number is, the more significant the enrichment

including organic acids (76), amino acid derivative (53), hydroxycinnamoyl derivatives (38), isoflavones (17), benzoic acid derivatives (14), terpenoids (4), catechin derivatives (4) and other disease-resistant metabolites, allelochemicals and signalling molecules.

We combined a multivariate statistical analysis of the VIP $\geq 1$ from the OPLS-DA and a univariate statistical analysis of the t-test $p$-value $<0.05$ to screen the
Table 2 Metabolite identification results

\begin{tabular}{|c|c|c|}
\hline Type & Number & Percentage (\%) \\
\hline Organic acids & 76 & 12.219 \\
\hline Nucleotide and derivates & 61 & 9.807 \\
\hline Amino acid derivatives & 53 & 8.521 \\
\hline Flavone & 40 & 6.431 \\
\hline Hydroxycinnamoyl derivatives & 38 & 6.109 \\
\hline Lipids_Glycerophospholipids & 34 & 5.466 \\
\hline Amino acids & 30 & 4.823 \\
\hline Lipids_Fatty acids & 23 & 3.698 \\
\hline Carbohydrates & 21 & 3.376 \\
\hline Flavonol & 21 & 3.376 \\
\hline Flavanone & 19 & 3.055 \\
\hline Lipids_Glycerolipids & 18 & 2.894 \\
\hline Isoflavone & 17 & 2.733 \\
\hline Vitamins & 17 & 2.733 \\
\hline Anthocyanins & 14 & 2.251 \\
\hline Benzoic acid derivatives & 14 & 2.251 \\
\hline Flavone C-glycosides & 13 & 2.090 \\
\hline Coumarins & 12 & 1.929 \\
\hline Phenolamides & 12 & 1.929 \\
\hline Alcohols and polyols & 9 & 1.447 \\
\hline Indole derivatives & 9 & 1.447 \\
\hline Quinate and its derivatives & 8 & 1.286 \\
\hline Nicotinic acid derivatives & 5 & 0.804 \\
\hline Alkaloids & 4 & 0.643 \\
\hline Catechin derivatives & 4 & 0.643 \\
\hline Cholines & 4 & 0.643 \\
\hline Terpenoids & 4 & 0.643 \\
\hline Tryptamine derivatives & 4 & 0.643 \\
\hline Pyridine derivatives & 3 & 0.482 \\
\hline Flavonolignan & 2 & 0.322 \\
\hline Others & 33 & 5.305 \\
\hline
\end{tabular}

significant differences in metabolites between different comparison groups [41]. The results for the metabolites with significant differences are shown in Table 3. When comparing group CK and group F, 11 metabolites were upregulated and 22 were downregulated. Compared with $\mathrm{AF}$, the number of upregulated and downregulated metabolites in $\mathrm{F}$ was 56 and 35.

Table 3 Statistics on the differential metabolites

\begin{tabular}{llll}
\hline Group & Up & Down & All \\
\hline CK-vs-F & 11 & 22 & 33 \\
F-vs-AF & 19 & 20 & 39 \\
CK-vs-AF & 16 & 14 & 30 \\
\hline
\end{tabular}


A cluster analysis and heat map were created after the data normalization of the different metabolites between the comparison groups, which could visually show the accumulation difference in the differential metabolites between the groups (Fig. 6). There were 30 different metabolites, including nicotinic acid and its derivatives, flavonoids, and benzoic acid and its derivatives. Many of these metabolites have been shown to be effective in the plant defence response, including terpenoids and phenylpropanoids $[13,51]$.

All the differential metabolites were enriched in metabolic pathways to obtain differential metabolic pathways. CK vs. F showed 38 enriched metabolic pathways, and they were significantly enriched in amino acid biosynthesis $(42.86 \%)$, metabolic pathways $(78.57 \%)$, secondary metabolite biosynthesis (57.14\%), monomer biosynthesis (14.29\%), acetaldehyde and dicarboxylic acid metabolism (14.29\%). During arginine and proline metabolism、tyrosine metabolism and arginine biosynthesis, the expression of arginine and tyrosine in Group $F$ was significantly downregulated. In addition, the expression of pantothenic acid in Group $\mathrm{F}$ was also downregulated during the biosynthesis of CoA and pantothenic acid.

A total of 38 metabolic pathways were enriched in $F$ vs. AF, with significant enrichment in purine metabolism (20.83\%), secondary metabolite biosynthesis (37.5\%), isoflavone biosynthesis (8.33\%), glucoside biosynthesis (8.33\%), lysine degradation (8.33\%), fatty acid degradation (4.17\%), pantothenic acid and CoA biosynthesis

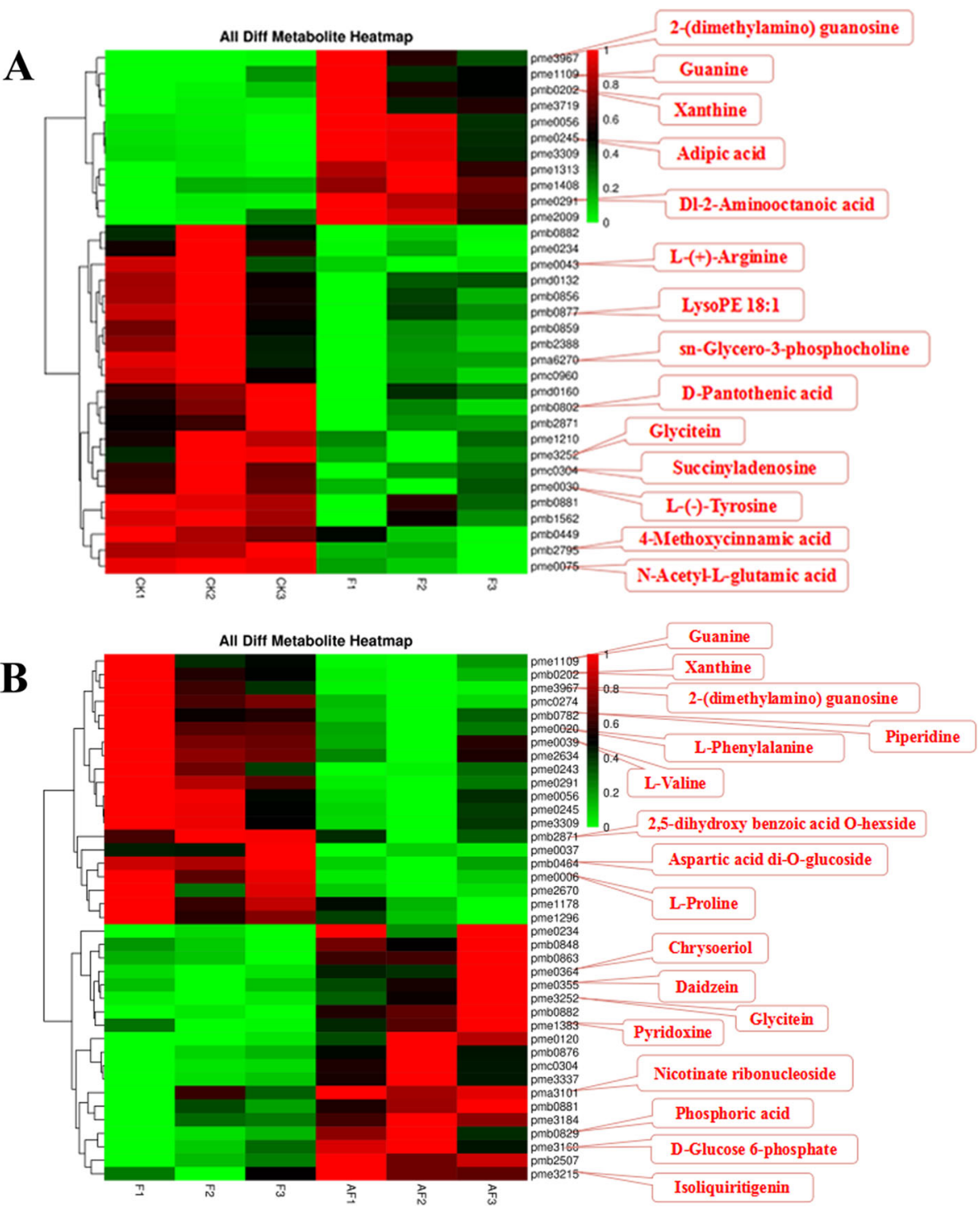

Fig. 6 Differential metabolite cluster heat maps of continuously cropped soybean roots during the high incidence of root rot. (A): CK-vs-F; (B): Fvs-AF. Each row in the figure represents a different metabolite, and each vertical column represents a component, with colours representing the different intensity of the metabolites from red to green to indicate the intensity of the difference from large to small 
(4.17\%), phenylalanine metabolism (4.17\%) and other pathways. The expression of D-glucose 6-phosphate in AF group was upregulated during the metabolism of phosphoinositol. The expression of 4-hydroxy-2-quinolinic acid in AF group was upregulated in the tryptophan metabolism pathway. In addition, during isoflavone metabolic pathway, daidzein and 7,4-dihydroxy, 6methoxy isoflavone (glycine) in AF group were also significantly upregulated.

From these findings, we can observe that the pathogen infection reduced the expression of organic acids and other metabolites and amino acid content in the soybean roots, resulting in serious plant disease and poor development. F. mosseae can induce and promote the expression of plant defence mechanisms and growth regulators, increase crop resistance, and be conducive to crop growth.

\section{Impact of $F$. mosseae treatments on integrated metabolites and transcript networks in soybean roots}

Secondary metabolites such as flavonoids could effectively help plants resist diseases, including protecting plants from pathogens, plants auxin transport and mutual recognition and cooperation between plants and microorganisms $[5,12,29]$. In mycorrhizal soybeans, $F$. mosseae strongly promoted the accumulation of flavonoids, such as flavonols, flavone, and anthocyanin. In the $\mathrm{CK}$ vs $\mathrm{F}$ group, the flavonoid biosynthesis-related genes $C H I$, chalcone synthase $(C H S)$, trans-cinnamate 4monooxygenase, coumaroyl quinate (coumaroyl shikimate) 3'-monooxygenase, caffeoyl-CoA Omethyltransferase, flavonoid 3 '-monooxygenase, and shikimate O-hydroxycinnamoyltransferase were upregulated. In the $\mathrm{F}$ vs. $\mathrm{AF}$ group, most genes were downregulated. In the interaction between plants and pathogens, Isoflavonoids not only act as signalling molecules for the symbiosis of nitrogen-fixing bacteria, but also inhibit the pathogen infection (plant antitoxin) [27].. $\mathrm{CHS}$ and $\mathrm{CHI}$ are key enzymes in isoflavone synthesis that play crucial roles in plant responses to various pathogens. Their expression efficiency in plants directly affects the isoflavone content. Soybeans contain 9 members of the CHS gene family, from CHS1 to CHS9, and CHS1 has 2 copies. Although members of this family are highly similar in sequence, they play different roles in plant development. CHS7 and CHS8 are primarily involved in isoflavone synthesis and metabolic pathways [54]. There are two primary types of $C H I$, of which CHI2 only exists in legumes. It can catalyse naringin chalcone and isoliquiritigenin to become naringenin and liquiritigenin, respectively. This finding is consistent with the biosynthesis of isoflavone [31]. In this study, the isoflavones were upregulated after the inoculation with $F$. mosseae, which alleviated the root rot (Fig. 7).

\section{Discussion}

Soybean root rot caused by $F$. oxysporum is a typical destructive soil-borne disease. It has been shown that AMF can enhance plant disease resistance and reduce the harm caused by pathogens. For example, Some authors have shown that all AMF inoculations could reduce the incidence of peanut (Arachis hypogaea Linn.) stem rot caused by Sclerotium rolfsii, including inoculations of Glomus etunicatum, Glomus mosseae, Glomus clarum, Glomus caledonium, Glomus fasciculatum and Gigaspora margarita; the disease severity was reduced by $37.8 \% \sim 64.7 \%$ under pot experiment conditions, and the disease severity was reduced by $30.6 \% \sim 47.2 \%$ under field testing [37]. Liu designed greenhouse experiments to study the effects of two types of AMF (G. intraradices and G. mosseae) on the disease resistance of tobacco. The results showed that the incidence and disease index of tobacco cyanosis after inoculating with G. intraradices and G. mosseae decreased in comparison with the control group without AMF inoculation [23]. Jie found that the DNA level of $F$. oxysporum in the roots and rhizospheric soil samples of soybean plants inoculated with $F$. mosseae decreased significantly, suggesting that $F$. mosseae had a strong inhibitory effect on $F$. oxysporum [16]. At present, there are few studies on the mechanism by which $F$. mosseae alleviates root rot. In this study, soybean HN48 (protein type) was used as the experimental material. To study how the mechanism of $F$. mosseae alleviates root rot, the time gradient sampling method was used to calculate and observe the incidence of soybean root rot; it was found that $F$. mosseae effectively reduced the root rot incidence. This result is consistent with Gao [9].

After being affected by various pathogenic organisms and adversity factors, plants can produce certain defence mechanisms to maintain their normal growth and development [48]. Plant disease resistance is a complex process, and the induction of some defence enzymes (such as POD, PAL, and SOD) is the most important physiological and biochemical resistance mechanism. These enzymes make plants resistant to pathogens by participating in the metabolism of disease-resistant secondary biomass (such as lignin, phenolics, and phytoalexin), or through the metabolism of active oxygen AOS in plants, or by directly inhibiting and killing pathogens [6]. The increase in POD activity can promote the oxidation of phenol to quinone, which is harmful to bacteria. PAL is one of the major enzymes of phenol metabolism, and it affects the synthesis of phenolic compounds. SOD can effectively scavenge oxygen free radicals and protect cells. In this experiment, the $P A L$ gene in the phylopanoid biosynthesis pathway was upregulated after being treated with $F$. oxysporum, which was a similar result to that of $\mathrm{Li}$ and Ozlem [21, 38]. 


\section{FLAVONOID BIOSYNTHESIS}

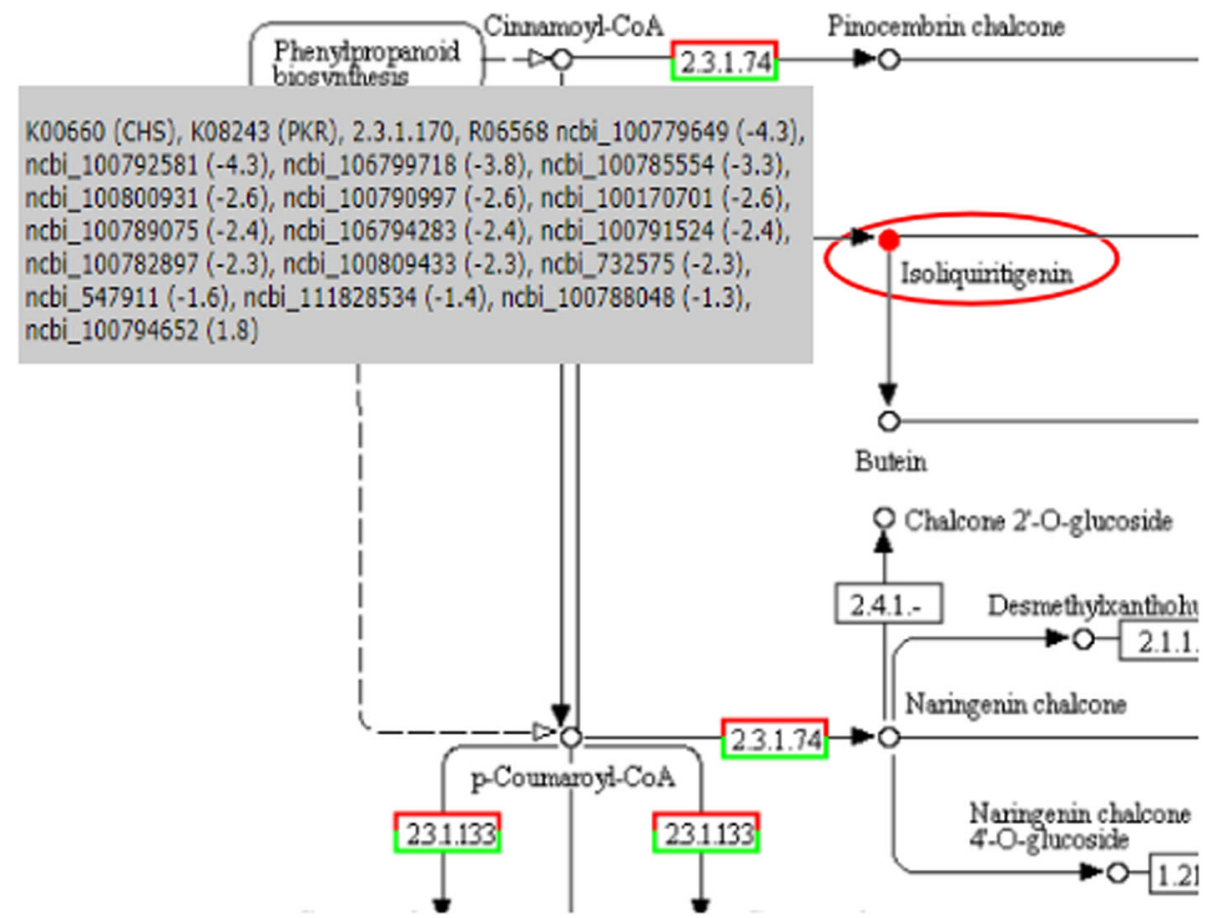

Fig. $7 \mathrm{CHS}$ and isoflavone in flavonoid biosynthesis. 2.3.1.74 represent CHS. The red circles mean metabolites are upregulated. The red box means genes upregulated, the green box means genes downregulated,and numbers of CHS genes in NCBI are showed in grey box

However, the $P A L$ gene was downregulated in the roots of plants treated with $F$. mosseae. We speculated that when the soybean roots were infected with the pathogen, F. oxysporum induced the upregulation of $P A L$ genes, but after the effect of $F$. mosseae, the continuous cropping disease was relieved and the activity of the $P A L$ genes decreased.

Isocitrate dehydrogenase (IDH) can catalyse the oxidative decarboxylation of isocitrate to generate $\alpha$ ketoglutarate and carbon dioxide and reduce the oxidized $\operatorname{NAD}(\mathrm{P})^{+}$to $\mathrm{NAD}(\mathrm{P}) \mathrm{H}$, and it is one of the key enzymes in the tricarboxylic acid cycle. Its activity has a great influence on the entire life metabolism of the organism. It has been reported that IDH plays an active role in responding to low temperature, drought and salt stress [20, 25]. In this study, the expression of $I D H$ genes in the TCA cycle and glutathione metabolism was upregulated after $F$. oxysporum infection, which was similar to the results of Leterrier et al. in their study on pea (Pisum sativum L.) leaves under low temperature stress and mechanical damage, in which the expression levels of NADP-IDH were increased by 70 and $40 \%$, respectively [20]. Therefore, we speculated that $I D H$ genes play an active role in plant resistance to stress, and protecting cells from adverse factor stress may be an important biological function of $I D H$.

The results in this study indicated that energy metabolism, including glycolysis, the pentose phosphate pathway, TCA and oxidative phosphorylation, were affected by pathogenic fungi. Under stress from the external environment, the primary metabolic function of the pentose phosphate pathway is reduced, and its primary function is to regulate the flow of the carbon source to a secondary metabolism pathway, such as synthetic phytoalexin, lignin and other secondary metabolism pathways [18]. The 6-phosphogluconate dehydrogenase (6-PGDH) pyrazole gets rid of alcohol, and the 2-deoxidation-D-ribose 1-phosphoric acid and 2-deoxidation-1-alpha-D-ribose phosphate in the pentose phosphate pathway were upregulated, and thus we speculated that the primary role of $6-\mathrm{PGDH}$ in plant disease resistance was to contribute five-carbon sugar compounds to the synthesis of phenolic compounds and other resistant substances. In addition, it also provided more NADPH-reducing power to improve plant resistance to pathogenic microbe infections [4, 35]. Notably, this result indicated that $F$. mosseae accelerated the energy metabolism by 
increasing the production of ATP. Furthermore, the accumulation of proline, 2-amino-3-methyl butyric acid, arginine, glycine, tyrosine, glucose-6-phosphate, and the contents of various organic acids were observed. Compared with the $\mathrm{CK}$ and AF groups, there was a general decreasing trend in the levels of most amino acids in the $\mathrm{F}$ group, which indicated that the metabolic activity of the soybean roots was inhibited, similar to Van et al.'s study on the metabolic response of Arabidopsis (Arabidopsis thaliana) roots [46]. AMF can effectively induce the accumulation of amino acids in soybean roots.

Plants respond to pathogens with a series of specific receptors and signals [28]. A cascade of mitogenactivated protein kinases (MAPK) plays a key role in transmitting signals from the outside to the inside of the cell [3]. Studies have shown that in Arabidopsis, transcriptional activation of Flg 22-induced receptor like kinase 1(FRK 1), WRK 22 and other downstream targets, thus causing their own defense [33, 40]. In this study, calcium-dependent protein kinase 1 , mitogen-activated protein kinase 1 and serine/threonine-protein kinase PBS1 were adjusted significantly in the CK vs. F groups, indicating that $F$. oxysporum can induce the expression of defence-related genes and limits the migration of the pathogen, and thus plants can become resistant to disease.

\section{Conclusions}

In this study, transcriptome and metabolomics analyses were used to study the variations in gene expression patterns and metabolites between continuously cropped soybean roots. Our results revealed that $F$. mosseae significantly reduced the incidence of root rot in continuously cropped soybeans, improving the disease resistance of these plants. In addition, F. mosseae could also promote the accumulation of resistance genes such as PAL, CYP73A, CCR, CHI, and IDH and metabolites such as daidzein, isoliquiritigenin, pyridoxine, isoflavonoid and other metabolites. Our results not only provide theoretical basis for revealing the molecular mechanisms of AMF alleviating soybean root rot, but they also provide a theoretical basis for the development and application of biological agents.

\section{Methods}

\section{Plant material and inoculation methods}

The test soybean seeds (HN48) were purchased from Heilongjiang Academy of Agricultural Sciences (Harbin City, Heilongjiang Province, China), a widely cultivated species in Heilongjiang. The experiment was conducted at the Sugar Industry Research Institute Experimental Station at the Harbin Institute of Technology in Heilongjiang province, China. Soil from soybean continuously cropped for 3 year was used in experiments.

The tested F. mosseae strain was isolated by our research group, and it was stored at the Wuhan Institute of Microbiology. China. The strain preservation number was no. CGMCC 3013. Before planting, alfalfa (Medicago sativa L.) was used to propagate the $F$. mosseae strain. The tested pathogen was $F$. oxysporum, a dominant fungus in soybean soil in Heilongjiang province, which was provided by the Key Laboratory of Microbiology, Heilongjiang University.

\section{Sample processing and collection}

Experiments were conducted using potted plants. The soil was sterilized for $1 \mathrm{~h}$ in a high-pressure sterilizing pot at $121{ }^{\circ} \mathrm{C}$ and cooled to room temperature. The surfaces of the soybean seeds were wiped with alcohol, surface-sterilized for $10 \mathrm{~min}$ in $5 \%$ sodium hypochlorite, and then washed with sterile deionized water four times for $10 \mathrm{~min}$ per time. The sterilized seeds were placed in $5 \mathrm{~kg}$ of sterilized soil in $50 \mathrm{~cm} \times 60 \mathrm{~cm}$ pots. Five seeds were planted in each pot, and three seedlings were kept after they grew out. Three treatments were set up:(1) Group (CK): sowing soybean seeds in sterilized soil; (2) Group (F): sowing soybean seeds in sterilized soil, 44 days after sowing (the soybeans were in the flowering stage), the soybean seeds were inoculated with $F$. oxysporum spore suspension by root injection. (3) Group (AF): $45 \mathrm{~g} \mathrm{~F}$. mosseae inoculants were mixed with the 5 $\mathrm{kg}$ of sterilized soil used to grow soybeans, and after 44 days, the soybean seeds were inoculated with $F$. oxysporum spore suspension by root injection. For each treatment, we planted 20 pots. The soybean roots were harvested at high incidence period (60 days after sowing) from the $0-20 \mathrm{~cm}$ soil depth. Specifically, three soybean root samples were randomly selected from each treatment and stored in $10 \mathrm{~mL}$ centrifuge tubes and kept into a $-80^{\circ} \mathrm{C}$ freezer until molecular analysis.

\section{Determining the incidence index of soybean root rot and the infection rate of AMF}

At 44 days after sowing, different root samples were randomly selected every 7 days. The root rot incidence index was counted according to the classification criteria of soybean root rot. The criteria are as follows: Grade 1: sporadic lesions; Grade 2: patches of sporadic lesions; Grade 3: the lesion area accounts for $25 \%$ of the total root area; Grade 4: the lesion area accounts for $30 \%$ of the total root area, the lesion area is continuous around the stem but the root is not necrotic; Grade 5: the lesion area accounts for more than 50\% of the total root area. The calculation formula of root rot incidence index is as follows: 


\section{Incidence index \\ $\sum($ Number of diease plants at each level $\times$ Disease level $)$ Plant number investigated $\times$ The number of the highest level $\times 100$}

Acid fuchsin staining was used to determine the AMF colonization rate [30]. At 44 days after sowing, different root samples were randomly selected every 7 days. The fibrous roots of soybean were washed and cut into a length of $1 \mathrm{~cm}$ and placed in a $5 \mathrm{~mL}$ centrifuge tube. 50 100 fibrous roots of soybean were randomly selected for staining, slicing and microscopic examination to observe the colonization of AMF in each treatment. The calculation formula of colonization rate is as follows:

$$
\text { Colonization rate }=\frac{\text { Number of infected root egments }}{\text { Total number of observed root egments }} \times 100 \%
$$

All values are expressed as the mean $\pm \mathrm{SD}$. The data were analysed by analysis of variance (ANOVA) followed by Tukey's HSD test using SPSS 23.0 to determine the significance of differences between different treatments $(P<0.05)$.

\section{RNA extraction and RNA sequencing analysis}

RNA extraction and sequencing analysis were performed as described by $\mathrm{Yu} \mathrm{CJ}$ et al. [56]. The total RNA was extracted by Trizol-based method [32] during a high incidence of soybean root rot (60 days after sowing). After that, the eukaryotic mRNA was enriched with oligonucleotide (dT), and the rRNA was removed with a Ribo Zero $^{\text {nx }}$ Magnetic Kit (Epicentre), to enrich the prokaryotic mRNA. Fragmented buffer was used to segment the enriched mRNA, reverse-transcribed into cDNA by random primers, then synthesized the second strand cDNA and purified it with QiaQuick-PCR extraction kit, endrepair, added poly (A) and connected to Illumina sequencing adapters. The ligation products were sizeselected by agarose gel electrophoresis, PCR-amplified, and sequenced using an Illumina $\mathrm{HiSeq}^{\mathrm{Tm}} 2500$ by Gene Denovo Biotechnology Co (Guangzhou, China).

To ensure high data quality, the raw sequence data were filtered to obtain clean data for the subsequent information analysis. In brief, the joint sequence was removed from the sequencing sequence, and reads with all A-bases were removed; reads with $\mathrm{N}$ ratios greater than $10 \%$ were removed and low-quality reads were removed (the number of bases with a mass value $\mathrm{Q} \leq 20$ accounted for more than $50 \%$ of the entire read). Then, the rRNA of each sample were removed from the reads and located to the reference genome via TopHat2 (version 2.0.3.12) [17], respectively. The alignment parameters were as follows: 1) Maximum read mismatch is 2; 2) The distance between mate-pair reads is $50 \mathrm{bp}$; 3) The error of distance between mate-pair reads is $\pm 80 \mathrm{bp}$ [15]. A differential gene expression analysis of the three groups was performed using the edge $\mathrm{R}$ package (https://www.r-bloggers.com/its-easy-to-cite-and-reference-r/). FDR and $\log 2 \mathrm{FC}$ were used to screen the differentially expressed genes. The screening conditions were FDR $<0.05$ and $|\log 2 \mathrm{FC}|>1$. The DEGs were annotated using the Mercator web tool [26] and then loaded onto MapMan software for a functional enrichment analysis [45]. After that, Gene Ontology (GO) and Kyoto Encyclopedia of Genes and Genomics (KEGG) pathway analyses were performed $[34,55]$.

\section{Metabolomics analysis Sample preparation and metabolite extraction}

All 9 obtained samples (three treatments, three biological replicates) were used for the metabolomics analysis. The freeze-dried samples were crushed using a mixer mill (MM 400, Retsch) with zirconia beads for 1.5 $\min$ at $30 \mathrm{~Hz}$. Then, $100 \mathrm{mg}$ of powder was weighed and extracted overnight at $4{ }^{\circ} \mathrm{C}$ with $1.0 \mathrm{~mL}$ of $70 \%$ aqueous methanol containing $0.1 \mathrm{mg} / \mathrm{L}$ lidocaine as the internal standard. Following centrifugation at $10000 \mathrm{~g}$ for $10 \mathrm{~min}$, the supernatants were absorbed and filtered (SCAA-104, $0.22-\mu \mathrm{m}$ pore size; ANPEL, Shanghai, China, www.anpel. com.cn/) before LC-MS/MS analysis. The same volume of all samples to be tested were mixed as Quality Control (QC) samples to detect the reproducibility of the results.

\section{Liquid chromatography electrospray ionisation tandem mass spectrometry (LC-ESI- MS/MS)}

Analysis of the extracted compounds using a LC-ESIMS/MS system (SCAA-104, $0.22 \mu \mathrm{m}$ pore size, ANPEL, Shanghai, China, www.anpel.com.cn/; UPLC, Shim-pack UFLC SHIMADZU CBM20A, http://www.shimadzu. com.cn/; MS/MS (Applied Biosystems 4500 QTRAP, http://www.appliedbiosystems.com.cn/). $2 \mu \mathrm{L}$ of samples were injected onto a Waters ACQUITY UPLC HSS T3 $\mathrm{C}_{18}$ column $\left(2.1 \mathrm{~mm}^{*} 100 \mathrm{~mm}, 1.8 \mu \mathrm{m}\right)$ operating at $40^{\circ} \mathrm{C}$ and a flow rate of $0.4 \mathrm{~mL} / \mathrm{min}$ [58]. Compounds were separated using the following gradient: 95:5 Phase A/ Phase B at 0 min; 5:95 Phase A/Phase B at 11.0 min; 5:95 Phase A/Phase B at $12.0 \mathrm{~min}$; 95:5 Phase A/Phase B at 12.1 min; 95:5 Phase A/Phase B at 15.0 min $[49,50]$. The effluent from the column was connected to an ESI triple quadrupole-linear ion trap (QTRAP)-MS.

LIT and triple quadrupole (QQQ) scans were acquired on a triple quadrupole-linear ion trap mass spectrometer (Q TRAP), AB Sciex QTRAP6500 System, equipped with an ESI-Turbo Ion-Spray interface, operating in a positive ion mode and controlled by Analyst 1.6.1 software (AB Sciex). The operation parameters were set as described by Shahzad $M$ et al. [43]. The monitoring mode was set to multiple-reaction monitoring (MRM). 


\section{Qualitative and quantitative analysis of metabolites}

The qualitative analysis of primary and secondary MS data was performed by searching public databases such as MassBank (http://www.massbank.jp/), KNApSAcK (http://kanaya.naist.jp/KNApSAcK/), HMDB (http:// www.hmdb.ca/) [52], MoToDB (http://www.ab.wur.nl/ moto/) and METLIN (http://metlin.scripps.edu/index. php) [59] (Zhu ZJ et al., 2013). The repetitive signals of $\mathrm{K}^{+}, \mathrm{Na}^{+}, \mathrm{NH}^{+}$, and other large molecular weight species were eliminated during the identification process. The exact $\mathrm{m} / \mathrm{z}$ of each $\mathrm{Q} 1$ (parent ion molecular weight) was obtained to facilitate the identification/annotation of metabolites [53]. The variable importance of the projection (VIP) score of the application orthogonal partial least squares discriminant analysis (OPLS-DA) model was used to rank the best differentiated metabolites between different treatments. a $P$ value of t-test of $<0.05$ and VIP $\geq 1$ were used to screen differential metabolites between samples $[49,50]$.

\section{Supplementary information}

Supplementary information accompanies this paper at https://doi.org/10. 1186/s12870-020-02647-2.

Additional file 1: Table S1. Statistical table showing read filtering information.

Additional file 2: Table S2. CK vs. F group metabolic pathway classification.

Additional file 3: Table S3. F vs. AF group metabolic pathway classification.

Additional file 4: Supplementary Figure S1. A multi-peak diagram of the multi-response monitoring (MRM) mode for metabolite detection (positive ions).

Additional file 5: Supplementary Figure S2. OPLS-DA score plots.

\section{Abbreviations}

UPLC: Ultra-performance liquid chromatography; MS/MS: Tandem mass spectrometry; DEGs: Differentially expressed genes; AMF: Arbuscular mycorrhizal fungi; GO: Gene Ontology; KEGG: Kyoto encyclopedia of genes and genomics; BP: Biological process; MF: Molecular function; CC: Cellular component; CYP73A: Trans-cinnamate monooxygenase; CCR: Cinnamyl-CoA reductase; PAL: Phenylalanine ammonia lyase; $\mathrm{CHI}$ : Chalcone isomerase; CHS: Chalcone synthase; POD: Peroxidase; SOD: Superoxidedismutase; AOS: Activated oxygen species; IDH: Isocitrate dehydrogenase; 6-PGDH: 6phosphogluconate dehydrogenase; MAPK: Mitogen-activated protein kinases; FRK1: Flg22-induced receptor- like kinase 1

\section{Acknowledgements}

Not applicable.

\section{Authors' contributions}

NG and $C L$ contributed equally to this work and share the first authorship; NG conceived, designed and performed the experiments; $C L$ analyzed the data; $\mathrm{CY}$ and $\mathrm{HS}$ drew the diagrams; NG polished the manuscript; $\mathrm{BC}$ wrote the paper. All authors read and approved the final manuscript.

\section{Funding}

This work was supported by the National Natural Science Foundation of China (No.31972502 and No.31570487). Funding body of No.31570487 support in the design of the study and collection, analysis, and interpretation of data and in writing the manuscript; but the founding body of No.31972502 did not play any roles in those.

\section{Availability of data and materials}

The datasets generated during the current study are available at the NCBI Sequence Read Archive (SRA) under accession number SRP240183.

Ethics approval and consent to participate

Not applicable.

Consent for publication

All authors agreed to publish.

\section{Competing interests}

The authors declare that they have no competing interests.

Received: 24 May 2020 Accepted: 14 September 2020

Published online: 21 October 2020

\section{References}

1. Agudeloromero P, Erban A, Rego C, Pablo Carbonell-Bejerano P, Nascimento $T$, Sousa $L$, et al. Transcriptome and metabolome reprogramming in Vitis vinifera cv. Trincadeira berries upon infection with Botrytis cinerea. J Exp Bot. 2015;66(7):1769-85.

2. Babu S, Bidyarani N, Chopra P, Monga D, Kumar R, Prasanna R, et al. Evaluating microbe-plant interactions and varietal differences for enhancing biocontrol efficacy in root rot disease challenged cotton crop. Eur J Plant Pathol. 2015;142(2):345-62

3. Boller T, Felix G. A renaissance of elicitors: perception of microbe-associated molecular patterns and danger signals by pattern-recognition receptors. Annu Rev Plant Biol. 2009;60(1):379-406.

4. Chen C. Study on the role of G6PD in the elicitor-mediated Taxol biosynthesis and the mechanism of its Antioxidation. Huazhong University of Science and Technology 2004.

5. Chen TZ, Lv YD, Zhao TM, Li N, Yang YW, Yu WG, et al. Comparative Transcriptome Profiling of a Resistant vs. Susceptible Tomato (Solanum lycopersicum) Cultivar in Response to Infection by Tomato Yellow Leaf Curl Virus. PLoS One. 2013:8(11):e80816.

6. Chen YP, Chen YF, Chen QZ, Huang X, Huang XL. Cloning, character ization and Expr ession of a phenylalanine Ammonialyase gene (M-PAL) from plantain (Musa ABB cv. Dongguandajiao). J Trop Subtrop Botany. 2007;15(5): $421-7$.

7. Cui JQ, Sun HB, Sun MB, Liang RT, Jie WG, Cai BY. Effects of Funneliformis mosseae on root metabolites and Rhizosphere soil properties to continuously-cropped soybean in the potted-experiments. Int J Mol Sci. 2018;19(8):2160

8. Floerl S, Majcherczyk A, Possienke M, Feussner K, Tappe H, Gatz C, et al. Verticillium longisporum infection affects the leaf apoplastic proteome, metabolome, and cell wall properties in Arabidopsis thaliana. PLoS One. 2012;7(2):e31435.

9. Gao P. Disease preventing and growth promoting effects of Arbuscular mycorrhizal fungi and rhizobium on alfalfa root rot and leaf spot. Lanzhou University 2017.

10. Guo YE, Zang F, Li F, Duan TY. Effects of grazing and AM fungi on growth and powdery mildew of Elymus nutans. Grassland Turf. 2018;38(2):43-50+ 57.

11. Hao YJ, Liu CY, Wang Y, Wang WL. Effect of Arbuscule Mycorrhizal Fungi on growth and Fusarium. Anhui Agricult Sci Bull. 2007;13(19):73-4.

12. Hassan S, Mathesius U. The role of flavonoids in root-rhizosphere signalling: opportunities and challenges for improving plant-microbe interactions. J Exp Bot. 2012;63(9):3429-44.

13. He J, Bouwmeester HJ, Dicke M, Kappers IF. Transcriptional and metabolite analysis reveal a shift in direct and indirect defences in response to spidermite infestation in cucumber (Cucumis sativus). Plant Mol Biol. 2020;103(70): 489-505.

14. Hwang S, Wang H, Gossen BD, Chang KF, Turnbull GD, Howard RJ. Impact of foliar diseases on photosynthesis, protein content and seed yield of alfalfa and efficacy of fungicide application. Eur J Plant Pathol. 2006;115(4): 389-99.

15. Javed I, Tan ZN, Li MX, Chen HB, Ma BY, Zhou X, et al. Estradiol alters hippocampal gene expression during the estrous cycle. Endocr Res. 2019;4: $1-18$. 
16. Jie WG, Yu WJ, Cai BY. Research on the relationship between Funneliformis mosseae and the root rot pathogen Fusarium Oxysporum in the continuous cropping of soybean. Soybean Sci. 2016;35(4):637-42.

17. Kim D, Pertea G, Trapnell C, Pimentel H, Kelley R, Salzberg ST. TopHat2: accurate alignment of transcriptomes in the presence of insertions, deletions and gene fusions. Genome Biol. 2013;14(4):R36.

18. Laura CL, Gutierrez-Carbonell E, Imai H, Abadía A, Uemura M, Abadía J, López-Millán AF. Effects of manganese toxicity on the protein profile of tomato (Solanum lycopersicum) roots as revealed by two complementary proteomic approaches, two-dimensional electrophoresis and shotgun analysis. J Proteome. 2018;185:51-63.

19. Leifheit EF, Veresoglou SD, Rillig MC. Multiple factors influence the role of arbuscular mycorrhizal fungi in soil aggregation-a meta-analysis. Plant Soil. 2014;374:523-37

20. Leterrier M, Rio LA, Corpas FJ. Cytosolic NADP-isocitrate dehydrogenase of pea plants: genomic clone characterization and functional analysis under abiotic stress conditions. Free Radic Res. 2007:41(2):191-9.

21. Li DQ, Chen ZY, Nie YF. Antifungal substances producted by a high-yielding mutant of Bs -916 and their effects inducing-resistance on rice plant. Acta Phytopathol Sinica. 2008;38(2):192-8.

22. Liu PF, Hui ZH, Dai T, Liang L, Liu XY. Metabolomics-a robust bioanalytical approach for phytopathology. Acta Phytopathol Sinica. 2018;4:433-44.

23. Liu XL, Xi XY, Shen H, Liu B, Guo T. Influences of Arbuscular Mycorrhizal (AM) Fungi inoculation on resistance of tobacco to bacterial wilt. Tobacco Sci Technol. 2014;49(5):23-30.

24. Liu XQ, Luo JQ. Advances of technologies and research in plant metabolomics. Sci Technol Rev. 2015;16:35-40.

25. Liu YH, Shi YS, Song YC, Wang TY, Li Y. Characterization of a stress-induced NADP-isocitrate dehydrogenase gene in maize confers salt tolerance inArabidopsis. J Plant Biol. 2010:53(2):107-12.

26. Lohse M, Nagel A, Herter T, May P, Schroda M, Zrenner R, et al. Mercator: a fast and simple web server for genome scale functional annotation of plant sequence data. Plant Cell Environ. 2014;37(5):1250-8.

27. Lozovaya W, Lygin AV, Zernova OV, Li S, Hartman GL, Widholm JM. Isoflavonoid accumulation in soybean hairy roots upon treatment with Fusarium solani. Plant Physiol Biochem (Paris). 2004:42(7-8):671-9.

28. Maria C, Morten P, John M. Mitogen-Activated Protein Kinase Signaling in Plants. Annu Rev Plant Biol. 2010;61(1):621-49.

29. María L, Falcone F, Sebastián P, Rius PC. Flavonoids: biosynthesis, biological functions and biotechnological applications. Front Plant Sci. 2012;3(222):222.

30. Mcgonigle TP, Millers MH, Evans DG. A new method which gives an objective measure of colonization of roots by vesicular-arbuscular mycorrhizal fungi. New Phytol. 1990;115:495-501.

31. Mckenzie KS, Rutger JN. Genetic analysis of amylose content, alkali spreading score, and grain dimensions in Rice1. Crop Sci. 1983;23(2):306-13.

32. Meng L, Feldman L. A rapid TRlzol-based two-step method for DNA-free RNA extraction from Arabidopsis siliques and dry seeds. Biotechnol J. 2010; 5(2):183-6.

33. Meng $X$, Zhang S. MAPK cascades in plant disease resistance signaling Annu Rev Phytopathol. 2013;51(1):245-66.

34. Moriya Y, Itoh M, Okuda S, Yoshizawa AC, Kanehisa M. KAAS: an automatic genome annotation and pathway reconstruction server. Nucleic Acids Res 35(Web Server). 2007: 35:182-185.

35. Nemoto Y, Sasakuma T. Specific expression of glucose-6-phosphate dehydrogenase (G6PDH) gene by salt stress in wheat (Triticum aestivum L.). Plant Sci (Shannon) 2000;158(1-2):0-60.

36. Ortiz N, Armada E, Azcon R. Contribution of arbuscular mycorrhizal fung and/or bacteria to enhancing plant drought tolerance under natural soil conditions: effectiveness of autochthonous or allochthonous strains. J Plant Physiol. 2011;174:87-96.

37. Ozgonen $\mathrm{H}$, Akgul DS, Erkilic A. The effects of arbuscular mycorrhizal fungi on yield and stem rot caused by Sclerotium rolfsii Sacc. In peanut. Afr J Agric Res. 2010;5(2):128-32.

38. Ozlem K, Yuen GY, Yuen. Induced Resistance as a Mechanism of Biological Control by Lysobacter enzymogenes Strain C3. Phytopathology. 2003;93(9): 1103.

39. Qian L, Yu WJ, Cui JQ. Funneliformis mosseae affects the root rot pathogen Fusarium oxysporum in soybeans. Acta Agricult Scand Section B Soil Plant Sci. 2015;65(4):321-8.

40. Rasmussen MW, Roux M, Petersen M, Mundy J. MAP kinase cascades in Arabidopsis innate immunity. Front Plant Sci. 2012;24(3):169.
41. Saccenti E, Hoefsloot HC, Smilde AK, Westerhuis JA, Hendriks MM Reflections on univariate and multivariate analysis of metabolomics data. Metabolomics. 2014;10(3):361-74.

42. Sarfir GE. The influence of vesicular arbuscular mycorrhiza on the resistance of onion to Phyrenochacta terreations Urbana: University of Illinois. 1968.

43. Shahzad M, Li YM, He PF, He PB. Unraveling the metabolite signature of citrus showing defense response towards Candidatus, Liberibacter asiaticus after application of endophyte Bacillus subtilis L1-21. Microbiol Res. 2020: 234. https://doi.org/10.1016/j.micres.2020.126425.

44. Siddiqui ZA, Akhtar MS. Biological control of root-rot disease complex of chickpea by AM fungi. Archiv für Pflanzenschutz. 2006;39(5):389-95.

45. Thimm O, Blasing O, Gibon Y, Nagel A, Meyer S, Stitt M, et al. Mapman: a user-driven tool to display genomics data sets onto diagrams of metabolic pathways and other biological processes. Plant J. 2004;37(6):914-39.

46. Van Dongen JT, Frohlich A, Ramirez-Aguilar SJ, Schauer N, Fernie AR, Erban A, et al. Transcript and metabolite profiling of the adaptive response to mild decreases in oxygen concentration in the roots of arabidopsis plants. Ann Bot. 2008;103(2):269-80.

47. Wang CX, Li XL, Song FQ, Wang GQ, Li BQ. Effects of arbuscular mycorrhizal fungi on fusarium wilt and disease resis-tance-related enzyme activity in cucumber seedling root. Chin J Eco-Agric. 2012;20(1):53-7.

48. Wang W, Hu YL, Xie JH. Cloning Expressionand Activation Analysis of Phenylalanine Ammonia-lyase Gene from Banana (Musaspp.AAA,Williams Mutant). Acta Laser Biol Sinica. 2009;18(3):341-8.

49. Wang XD, Xiao G, Zhang ZQ, Xiao N, Chen H, Guan CY. Application of Transcriptomics and proteomics correlation analysis in Plant research. Genomics Appl Biol. 2018a;37(1):432-9.

50. Wang Y, Zhang XF, Yang SL, Yuan YB. Metabolite and Transcriptome analyses indicate the involvement of lignin in programmed changes in peach fruit texture. J Agricult Food Chem. 2018b;66(48):12627-40.

51. Winterberg B, Du Fall LA, Song XM, Pascovici D, Care N, Molloy MP, et al. The necrotrophic effector protein SnTox3 re-programs metabolism and elicits a strong defence response in susceptible wheat leaves. BMC Plant Biol. 2014;14:215.

52. Wishart DS, Jewison T, Guo AC, Wilson M, Knox C, Liu Y, et al. HMDB 3. 0-the human metabolome database in 2013. Nucleic Acids Res. 2013; 41(D1):D801-7.

53. Xue J, Balamurugan S, Li DW, Liu YH, Zeng H, Wang L, et al. Glucose-6phosphate dehydrogenase as a target for highly effiffifficient fatty acid biosynthesis in microalgae by enhancing NADPH supply. Metab Eng. 2017; $41: 212-21$.

54. Yi JX, Derynck MR, Chen L, Dhaubhadel S. Differential expression of CHS7 and CHS8 genes in soybean. Planta. 2010;231(3):741-53.

55. Young MD, Wakefield MJ, Smyth GK, Oshlack A. Gene ontology analysis for RNA-seq: accounting for selection bias. Genome Biol. 2010;11(2).

56. Yu CJ, Zhao XW, Qi G, Bai ZT, Wang Y, Wang SM, Ma YB, Liu Q, Hu RB, Zhou GK. Integrated analysis of transcriptome and metabolites reveals an essential role of metabolic flux in starch accumulation under nitrogen starvation in duckweed. Biotechnol Biofuels. 2017;10(1). https://doi.org/10.1186/s13068017-0851-8.

57. Zhang CJ, Liao SQ, Song H, Zhao X, Han YP, Liu Q, et al. Identification for resistance to root rot caused by Fusarium Oxysporum in soybean Germplasm and physiological analysis. Soybean Sci. 2017;03:121-6.

58. Zhang Q, Shi Y, Ma L, Yi X, Ruan J. Metabolomic analysis using ultraperformance liquid chromatography-Quadrupole-time of flight mass spectrometry (UPLC-Q-TOF MS) uncovers the effects of light intensity and temperature under shading treatments on the metabolites in tea. PLoS One. 2014;9(11):e112572

59. Zhu ZJ, Schultz AW, Wang J, Johnson CH, Yannone SM, Patti GJ, Siuzdak G, et al. Liquid chromatography quadrupole time-of-flight mass spectrometry characterization of metabolites guided by the METLIN database. Nat Protoc. 2013:8(3):451-60.

\section{Publisher's Note}

Springer Nature remains neutral with regard to jurisdictional claims in published maps and institutional affiliations. 